\title{
THE EXPRESSION OF TSLP RECEPTOR IN CHRONIC RHINOSINUSITIS WITH AND WITHOUT NASAL POLYPS
}

\author{
M. BOITA', M GARZARO', L. RAIMONDO², G. RIVA², J. MAZIBRADA ${ }^{3}$, B. VIZIO', \\ G. BELLONE ${ }^{1}$, G. PECORARI ${ }^{2}$, C. BUCCA ${ }^{4}$, G. ROLLA $^{5}$ and C. GIORDANO ${ }^{2}$ \\ 'Molecular Biology Laboratory, Clinical Physiopathology Department, University of Turin; \\ ${ }^{2}$ Ist ENT Division, Clinical Physiopathology Department, University of Turin; ${ }^{3}$ Department of \\ Biomedical Sciences and Human Oncology, University of Turin; ${ }^{4}$ Biomedical Science and Human \\ Oncology, Internal Medicine V, University of Turin; ' ${ }^{5}$ Allergy and Clinical Immunology, Department \\ of Biomedical Science and Human Oncology, University of Turin, Italy
}

Received May, 4, 2011 - Accepted July 6, 2011

The first two authors contributed equally to the paper

Chronic Rhinosinusitis with or without Nasal Polyps (CRSwNP and CRSsNP) may be characterized by different cytokine profiles. Generally, Th2 cytokines and eosinophilic infiltration have been reported to be more specific of CRSwNP compared to CRSsNP, where neutrophils seem to play a major role. The epithelial cell-derived thymic stromal lymphopoietin (TSLP) has been recently identified as a key factor in Th2-inflammatory response. The aim of this study is to investigate the expression of TSLP Receptor (TSLP R) in surgical specimens obtained from patients affected by CRSwNP $(n=10)$ and $\operatorname{CRSsNP}(n=$ 5) by immunohistochemical techniques (immunostaining score, IS). TSLP R expression was significantly higher in the inflammatory infiltrate and in the epithelial cells of CRSwNP, CRSsNP patients compared to the control group (IS $4.5 \pm 0.68,4.4 \pm 1.44$ and $0.43 \pm 0.3$ respectively, $p=0.0024$ for inflammatory infiltrate and IS $5.8 \pm 0.92,7.8 \pm 2.06$ and $0.86 \pm 0.55$ respectively, $p=0.0018$ for epithelial cells). No significant difference was observed in IS of inflammatory infiltrate and epithelial cells in CRSwNP compared to CRSsNP. Very low IS for TSLP $R$ was found in connective tissue of all the samples, with no difference among the groups. TSLP receptor is highly expressed in CRS compared to controls and independently from the polyps suggesting an early common inflammatory pathway in the two CRS phenotypes.

Chronic rhinosinusitis is a significant and increasing health problem with a prevalence of $10.9 \%$ in the European countries. It is a disease that can significantly affect health-related quality of life and daily functioning, representing a huge financial burden to society and healthcare systems as a result of the direct and indirect costs $(1-2)$. The relative roles of initiating events, environmental factors, and host susceptibility factors are all currently unknown (3). Chronic rhinosinusitis (CRS) is a multifactorial disease: contributing factors can be mucociliary impairment, bacterial infection, allergy, swelling of the mucosa for other reasons or, rarely, physical obstruction caused by anatomical variations in the

Key words: TSLP, TSLP receptor, nasal polyps, immunohistochemistry

Mailing address: Luca Raimondo, MD

1" ENT Division,

Department of Clinical Physiopathology,

San Giovanni Battista Hospital,

Via Genova 3, 10126 Turin, Italy

Tel: ++390116336688 Fax: ++390116336650

e-mail: 1.raimondo@hotmail.it

0394-6320 (2011)

Copyright $\odot$ by BIOLIFE, s.a.s.

This publication and/or article is for individuat use only and may not be further reproduced without written permission from the copyright holder. Unauthorized reproduction may result in financial and other penalties 
nasal cavities or paranasal sinuses.

The reason why polyps develop in some patients and not in others remains unknown; nasal polyps consist of connective tissue, edema and inflammatory cells such as eosinophils (the most common), neutrophils, mast cells, plasma cells, lymphocytes and monocytes. Nasal polyps have a strong tendency to relapse after functional endoscopic sinus surgery (FESS), suggesting different pathogenic mechanisms underlying CRS with and without nasal polyps (CRSwNP and CRSsNP) (4-5). Actually nasal polyps have been associated with IL5, local nasal IgE production, eosinophils, eotaxin, and eosinophil cationic protein (ECP) (Th2 driven disease), whereas in CRSsNP a less defined Th2 profile, neutrophil infiltration, INF $\gamma$ and TGF $\beta$ production have been reported (6-7).

The epithelial cell-derived thymic stromal lymphopoietin (TSLP) has been recently identified as a key factor in Th2-inflammatory response: it is a cytokine which is mainly expressed by epithelial cells in the thymus, lung, skin, intestine and tonsils. Its expression may be induced by different exogenous/endogenous stimuli, as well as pathogens, traumas, infections, allergens, Toll Like Receptor Ligands (TLR-ligands), pro-inflammatory and Th2 cytokines (8).

TSLP receptor (TSLP R) is expressed on several immune cells, such as dendritic cells (DCs), B cells, T cells, mast cells, natural killer-T (NK-T) and monocytes, and on many organ tissues such as heart, skeletal muscle, kidney and liver. The receptor is a heterodimeric complex made up of two chains, TSLP R and IL 7R $\alpha$ and its phosphorilation activates STAT5 pathway (8).

TSLP endows DCs to induce the differentiation of inflammatory Th2 cells up-regulating co-stimulatory molecules (CD40, CD80), MHC II molecules and OX40 ligand (OX40L) (8-10). A pathogenetic role of TSLP in some Th2 driven diseases like asthma (11-12) and atopic dermatitis (AD) (13-16) have been recently suggested.

Our hypothesis is that TSLP may play an important role also in CRS pathogenesis, where epithelial barrier of sinus mucosal surface may initiate inflammatory response by secreting various cytokines and chemokines, which regulate innate immune cells.
Increased levels of TSLP in nasal mucosa of patients affected by allergic rhinitis have been reported by Mou (17-18) and, in a recent study, Liu et al. showed high levels of TSLP in nasal epithelial layer of patients with nasal polyps (19).

In the present study we wanted to investigate whether the expression of TSLP receptor was increased in patients with CRS compared to controls and whether there was a difference in TSLP $R$ expression in CRSwNP compared to CRSsNP. To this end, the expression of TSLP R was analyzed by immunohystochemical technique on surgical specimens of sinus biopsies obtained from patients affected by CRSwNP and CRSsNP and from controls (subjects who underwent cosmetic rhinoplasty).

\section{MATERIALS AND METHODS}

\section{Patients}

Between January and July 2010 at the First ENT Division of the University of Turin-Italy, 15 consecutive Caucasian patients (10 male: $67 \%$; and 5 female: $33 \%$ ) with a mean age of $51.46 \pm 13$ years (range $34-78$ years) affected by chronic rhino-sinusitis (CRS) with and without nasal polyps were enrolled in this prospective study which was approved by the local research committee (Table I). Each patient gave written informed consent. Exclusion criteria were: odontogenic CRS and nasal polyps with clinical aspects of inverted papilloma. Diagnosis of CRSwNP and CRSsNP was made by ENT anamnesis, ENT physical and fibre optical examination and by sinuses CT scan, according to European Position Paper on Rhinosinusitis 2007 criteria (Table II). The allergic status of all patients was investigated by means of cutaneous prick and patch tests.

Each patient was firstly treated with at least one cycle of oral antibiotics (penicillin/cephalosporin/ fluoroquinolones), oral steroids (metilprednisone) associated with intranasal corticosteroids (mometasone furoate, fluticasone furoate, budesonide) and nasal washing. After treatment failure all the patients were recruited for surgical intervention. No patients had been surgically treated previously.

Surgical treatment consisted in functional endoscopic sinus surgery (FESS), in order to erase the polyps and to clear all the involved paranasal sinuses. The procedural technique was that described by Graz School (20). Biopsy specimens were collected from ostio-meatal complex mucosa in patients affected by CRSsNP, from nasal polyp in patients with CRSwNP and from nasal respiratory mucosa of the control group (subjects who had undergone 
cosmetic rhinoplasty or who had uncorrelated pathologies, obtained from the Pathological Anatomy Division of the University of Turin); all specimens were immediately placed in a $10 \%$ buffered formalin solution, routinely processed, and embedded in paraffin; 4- $\mu$ m-thick consecutive sections were cut for the study.

\section{Immunohistochemistry}

Samples were deparaffinized in xylene and rehydrated in a series of graded alcohols. The sections were treated with a $3 \%$ solution of $\mathrm{H}_{2} \mathrm{O}_{2}$ for 30 minutes to inhibit endogenous peroxidase activity. Non specific binding sites were blocked by pre-incubation with fetal bovine serum for 25 minutes at room temperature. Reacted tissue sections were then incubated with $100 \mu \mathrm{l}$ of polyclonal goat anti-human TSLP R (R\&D System, Abingdon, UK; dilution $1: 6,6$ ) for $1.5 \mathrm{~h}$ at room temperature.

The primary antibody was replaced by fetal bovine serum in negative controls, whereas normal human liver specimens were used as positive controls.

Biotinylated rabbit-antigoat IgG $(\mathrm{H}+\mathrm{L})$ was obtained from Sigma (Sigma Pharmaceutical Ltd., South Croydon, Australia), and the avidin-biotin peroxidase complex kit was from DAKO LSAB (Dako, Carpinteria, Calif). The sections were then treated for $30 \mathrm{~min}$ at room temperature with biotinylated rabbit-antigoat immunoglobulin (dilution 1:2000), followed by incubation with avidinbiotin peroxidase complex solution for $15 \mathrm{~min}$ and diaminobenzidine tetrahydrochloride as chromogen. The slides were finally counterstained with Mayer's hematoxylin for 5 seconds, dehydrated, and mounted in Clarion (Biomeda, Foster City, California).
Healthy nasal mucosa samples were used as control group and analysed as described for the CRS specimens.

\section{Interpretation of immunohistochemical stains}

TSLP R expression was interpreted semi-quantitatively evaluating the specimens at three different levels: the inflammatory infiltrates, the respiratory epithelium and the stromal/fibroblastic component (connective tissue), using a grade for each level: grade 0 (1-10\% of positive cells), grade 1 (11-25\% of positive cells), grade $2(26-50 \%$ of positive cells), grade 3 (51-75\% of positive cells), grade 4 (76-100\% of positive cells). After detecting the intensity of the inflammatory infiltrates, the staining intensity for the three cell types was scored as 0 (negative), 1 (weak), 2 (medium), and 3 (strong). The immunoreactivity score was determined by multiplying staining intensity score by grade score (intensity $\times$ grade score: maximum immunostaining score (IS) 12).

\section{Statistical analyses}

All statistical analyses were carried out using GraphPad Prism 4. For normal distribution data, oneway ANOVA was used for determining the statistical significance of differences in TSLP $R$ expression in the inflammatory infiltrates and respiratory epithelial cells among CRSwNP, CRSsNP and the control group (probability value of $\mathrm{p}<0.05$ was considered statistically significant). For non-normal distribution, one-way ANOVA with Kruskal-Wallis test was performed. Furthermore, multiple comparison analysis was always performed by the Student's $t$-test adopting the Bonferroni method to have a stricter criterion on whether to accept an

Table I. Patients 'characteristics and surgical procedure.

\begin{tabular}{|l|c|}
\hline & Number of patients (\%) \\
\hline Inhalants Allergy & $8(53)$ \\
\hline Allergic Asthma & $6(40)$ \\
\hline Clinical Diagnosis \\
CRSwNP & $10(67)$ \\
CRSsNP & $5(33)$ \\
\hline Paranasal sinuses involvement & \\
Ethmoidal CRS & $3(23)$ \\
Maxillary CRS & $1(7)$ \\
Ethmoidal-maxillary CRS & $11(70)$ \\
\hline Histological diagnosis & \\
Inflammatory polyps & $10(67)$ \\
Chronic mucosal inflammation & $5(33)$ \\
\hline Surgical procedure (FESS) & \\
Polipectomy & $10(67)$ \\
Middle Antrostomy & $12(80)$ \\
Ethmoidectomy & $14(93)$ \\
\hline
\end{tabular}


Table II. Adapted from EPOS 2007: recommendations for the diagnosis of CRS.

Subjective assessment of rhinosinusitis: symptoms (duration of symptoms $>12$ weeks without their complete resolution)

- $\quad$ Nasal blockage, congestion or stuffiness;

- Nasal discharge or postnasal drip, often mucopurulent;

- Facial pain or pressure, headache, and

- Reduction/loss of smell.

Physical examination

- $\quad$ Anterior rhinoscopy

- $\quad$ Endoscopy

- Imaging (facial bones CT scan)

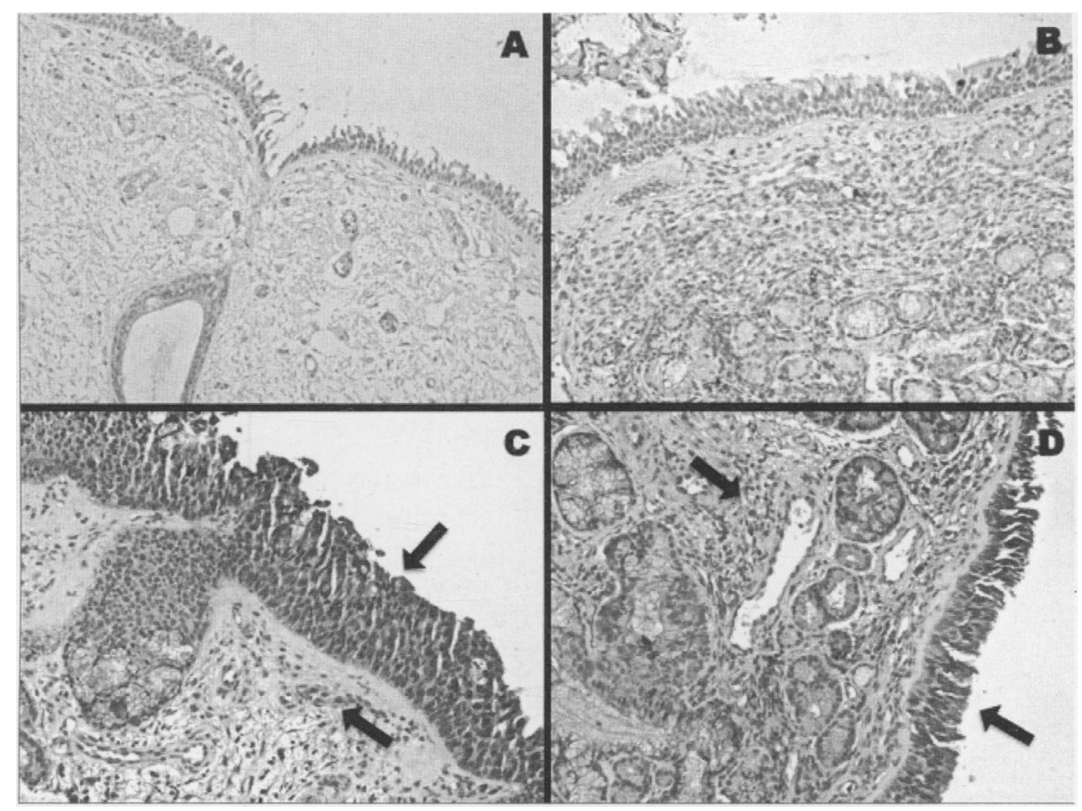

Fig. 1. TSLP $R$ immunostaining. Nasal mucosa from healthy subjects $(\boldsymbol{A}-\boldsymbol{B})$ : negative staining in epithelial and inflammatory cells; nasal mucosa from CRSSNP subjects (C-D): intense staining density interesting the epithelial layer and the inflammatory infiltrate, black arrows indicate the massive epithelial cells staining and the inflammatory cells staining; (original magnification $\times 200$ ).

effect as significant $(p<0.016)$.

\section{RESULTS}

In sinus bioptic samples of CRS patients eosinophilic infiltration with scattered mast cells and histiocytes was present, compared to a few lymphocytes in healthy controls.

TSLP R expression was evaluated separately in inflammatory infiltrate, respiratory epithelium, and connective tissue (stromal cells and fibroblasts). In CRS, TSLP R expression appeared generally as 


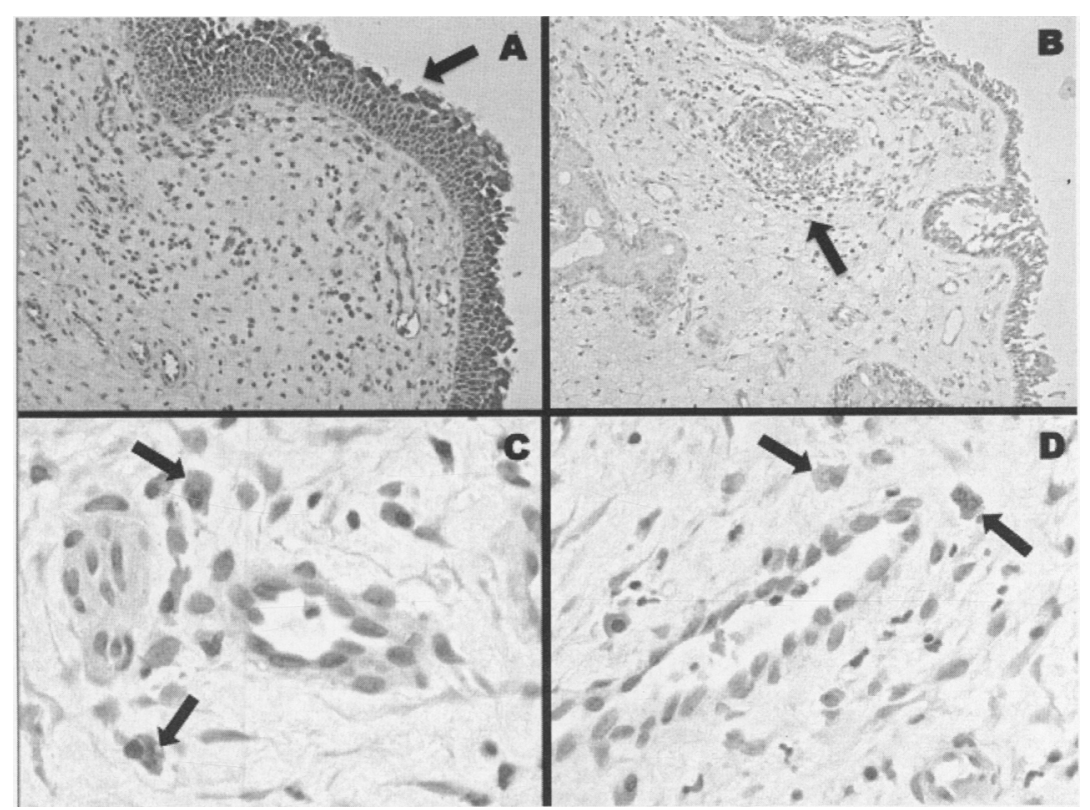

Fig. 2. TSLP R immunostaining. Nasal polyps from CRSwNP subjects: intense staining grade in epithelial cells (black arrows in panel $\boldsymbol{A}$ ) and in the inflammatory infiltrate (black arrow in panel $\boldsymbol{B}$ ), (original magnification $\times 200$ ); inflammatory infiltrate of nasal polyps from CRSwNP subjects $(\boldsymbol{C}$-D): black arrows show the Golgian dot like positivity in inflammatory cells (original magnification $x 400$ ).
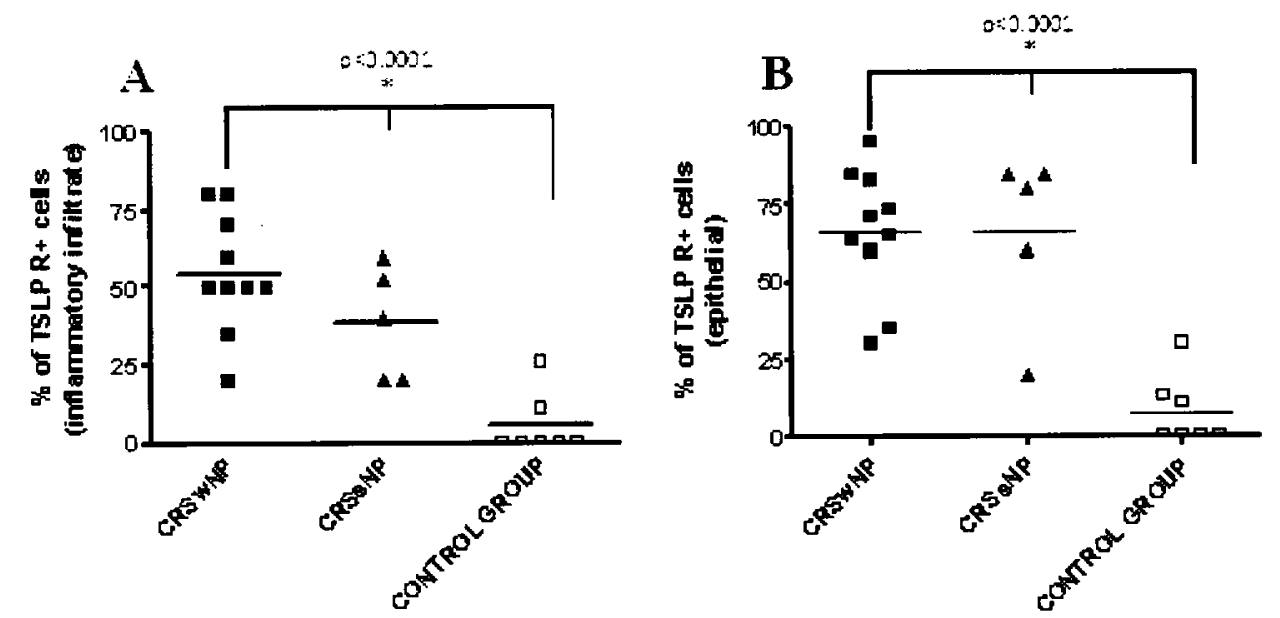

Fig. 3. Single and mean values of TSLP $R$ percentage of positive cells in (A) inflammatory infiltrates, (B) epithelial cells.

apical granular cytoplasmic staining in epithelial cells and as widespread granular cytoplasmic staining in inflammatory cells underlying respiratory epithelium (Fig. 1). In a few pathological specimens, a Golgian dot like staining was observed in inflammatory cells (Fig. 2).

An increased percentage of TSLP $R$ positive cells was observed in inflammatory and epithelial cells of CRSwNP and CRSsNP compared to control group $(54.5 \pm 5.9 \%, 38.4 \pm 8.1 \%$ and $5.3 \pm 3.8 \%, \mathrm{p}<$ 0.0001 positive inflammatory cells and $66.1 \pm 6.6 \%$, $66 \pm 12.4 \%, 7.7 \pm 4.3 \%, \mathrm{p}<0.0001$ positive epithelial cells respectively). No significant difference was observed between CRSwNP and CRSsNP in either inflammatory or epithelial cells (Fig. 3).

Immunostaining score (IS) (staining intensity $x$ 

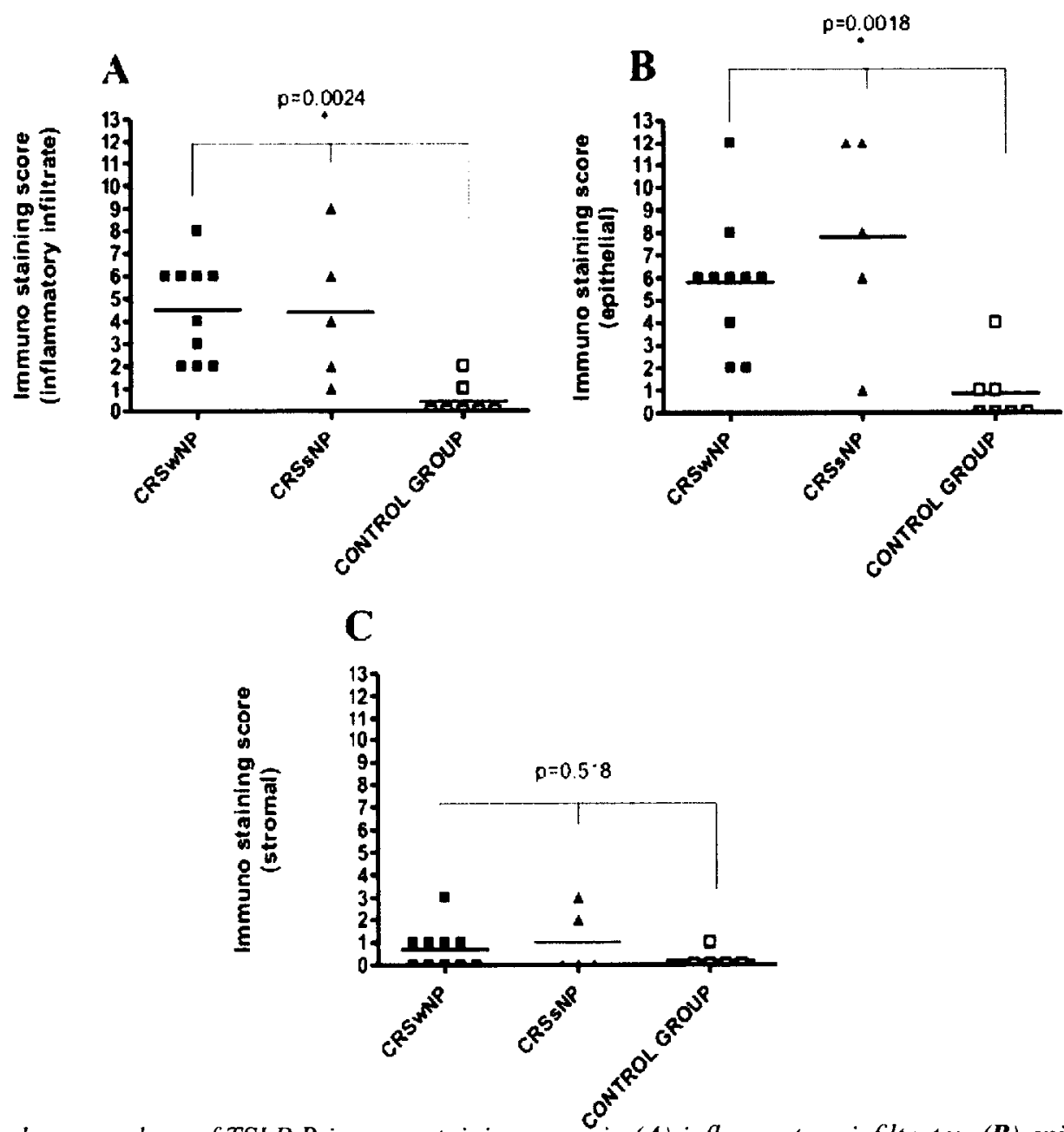

Fig. 4. Single and mean values of TSLP $R$ immunostaining score in (A) inflammatory infiltrates, (B) epithelial cells and (C) stromal/fibroblastic component.

grade score, see Methods) of inflammatory infiltrate was significantly higher in CRSwNP and CRSsNP

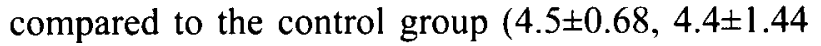
and $0.43 \pm 0.3$ respectively, $p=0.0024$ ), with no significant difference between CRS subtypes. IS of epithelial cells also was significantly higher in CRSwNP and CRSsNP compared to the control group $(5.8 \pm 0.92,7.8 \pm 2.06$ and $0.86 \pm 0.55$ respectively, $\mathrm{p}=$ 0.0018 ) with no significant difference between CRS subtypes (Fig. 4, panel A and B).

TSLP $R$ expression could not be appreciated at all, or the staining intensity was very low in the connective tissue of all the groups (Fig. 4, panel C).

\section{DISCUSSION}

Our results show that TSLP R is barely expressed in normal sinus tissue, whereas it is highly expressed in CRS, both in inflammatory and epithelial cells, with no significant difference between CRS subtypes (CRSwNP and CRSsNP). The cells with the highest TSLP R immunostaining score were eosinophils, mast cells and histiocytes in accordance with the data reported by Allakhverdi and coll. who showed that eosinophils and mast cells express the functional TSLP R complex and are able to respond to TSLP signals in the presence of inflammatory environment 
in a dose-dependent manner (21-23). We did not observe any TSLP receptor immunostaining in the connective tissue either in CRS or in healthy controls. Our results suggest a leading role of epithelial cells in addressing inflammatory response towards a Th2 pattern, as supported by the highest TSLP R expression observed in eosinophils and mast cells.

We found that TSLP $R$ was equally highly expressed in CRSwNP and CRSsNP, suggesting a common pathway in the inflammatory response which starts from the epithelial barrier and through TSLP-TSLP $R$ interaction drives the nasal mucosa through a Th2-inflammatory response. In our series we could not note any difference in the inflammatory infiltrate, which was mainly eosinophilic, either in CRSwNP or in CRSsNP. The pathogenetic mechanisms, which lead to the development of nasal polyps, are still unknown and probably involve different cytokines, like TNF $\alpha$ or IL $1 \beta$, and growth factors. Transforming growth factor-beta (TGF $\beta$ ) has been implicated as an important factor in remodeling processes involved in chronic sinus disease, and plays as a main switch for different remodeling patterns in chronic sinus disease (24).

To our knowledge, no previous report has investigated the TSLP R expression in CRS patients with or without nasal polyps.

In conclusion, this study suggests a critical role for TSLP as a driving factor in the pathogenesis of CRS, supported by the massive presence of its receptor both in the inflammatory cells and epithelial layer. The emerging concept of tissue-specific control of immunity, with TSLP secretion at the epithelial level acting as an initial factor in the CRS cascade, can partially explain the early stages of the disease. Further studies on the immune mechanisms involved in nasal polyps formation are required.

\section{REFERENCES}

1. Hastan D, Fokkens WJ, Bachert C, et al. Chronic rhinosinusitis in Europe - an underestimated disease. A GA2LEN study. Allergy 2011; Epub ahead of print.

2. Eloy P, Porrier AL, De Dorlodot C, et al. Actual concepts in rhinosinusitis: a review of clinical presentations, inflammatory pathways, cytokine profiles, remodeling and management. Curr Allergy
Asthma Rep 2011; 11:146-62.

3. Fokkens W, Lund V, Mullol J. European Position Paper on Rhinosinusitis and Nasal Polyps group. European position paper on rhinosinusitis and nasal polyps 2007. Rhinol Suppl 2007; 20:1-136.

4. Benninger MS. Rhinitis, sinusitis, and their relationships to allergies. Am J Rhinol 1992; 6:3743.

5. Huvenne W, Van Bruaene N, Zhang N, et al. Chronic rhinosinusitis with and without nasal polyps: what is the difference? Curr Allergy Asthma Rep 2009; 9: 213-20.

6. Van Zele T, Claeys S, Gevaert P, Van Maele G, Holtappels G, Van Cauwenberge P, Bachert C. Differentiation of chronic sinus diseases by measurement of inflammatory mediators. Allergy 2006; 61:1280-9.

7. Bachert C, Gevaert P, Holtappels G, Cuvelier C, Van Cauwenberge $P$. Nasal polyposis: from cytokines to growth. Am J Rhinol 2000; 14:279-90.

8. He R, Geha RS. Thymic stromal lymphopoietin. Ann NY Acad Sci 2010; 1183:13-24.

9. Wang YH, Liu YJ. Thymic stromal lymphopoietin, OX40-ligand, and interleukin-25 in allergic responses. Clin Exp Allergy 2009; 39:798-806.

10. Ito T, Wang YH, Duramad O, et al. TSLP-activated dendritic cells induce an inflammatory $T$ helper type 2 cell response through OX40 ligand. J Exp Med 2005; 202:1213-23.

11. Rochman Y, Leonard WJ. Thymic stromal lymphopoietin: a new cytokine in asthma. Curr Opin Pharmacol 2008; 8:249-54.

12. Ying S, O'Connor B, Ratoff J, et al. Expression and cellular provenance of thymic stromal lymphopoietin and chemokines in patients with severe asthma and chronic obstructive pulmonary disease. J Immunol 2008; 181:2790-8.

13. Soumelis V, Reche PA, Kanzler H, et al. Human epithelial cells trigger dendritic cell mediated allergic inflammation by producing TSLP. Nat Immunol 2002; 3:673-80

14. Li M, Messaddeq N, Teletin M, Pasquali JL, Metzger $D$, Chambon P. Retinoid X receptor ablation in adult mouse keratinocytes generates an atopic dermatitis triggered by thymic stromal lymphopoietin. Proc Natl Acad Sci USA 2005; 102:14795-800. 
15. Piancatelli D, Bellotta L, Del Beato T, Duse M, Della Penna MR. Total IL-12 levels are increased in pediatric atopic dermatitis: correlations with age and disease severity. Int J Immunopathol Pharmacol 2008; 21:359-66.

16. Hartgring S, Willis C, Dean C Jr, Broere F, Van Eden W, Bijlsma J, Lafeber F, Van Roon J. TSLP and its receptor play a critical proinflammatory role in autoimmune arthritis. Arthritis Rheum 2011; 63:1878-87.

17. Marseglia GL, Grignani M, Civallero P, Colombo B, Di Gioacchino M, Marchi A, Perrone A, Ciprandi G. Consequences of long-lasting persistent allergic rhinitis in adolescents. Int $J$ Immunopathol Pharmacol 2008; 21:761-65.

18. Mou Z, Xia J, Tan Y, Wang X, Zhang Y, Zhou B, $\mathrm{Li} \mathrm{H}$, Han D. Overexpression of thymic stromal lymphopoietin in allergic rhinitis. Acta Otolaryngol 2009; 129:297-301.

19. Liu T, Li TL, Zhao F, Xie C, Liu AM, Chen X, Song C, Cheng L, Yang PC. Role of thymic stromal lymphopoietin in the pathogenesis of nasal polyposis.
Am J Med Sci 2011; 341:40-7.

20. Stammberger H, Posawetz W. Functional endoscopic sinus surgery. Concept, indications and results of the Messerklinger technique. Eur Arch Otorhinolaryngol 1990; 247:63-76.

21. Allakhverdi Z, Comeau MR, Jessup HK, et al. Thymic stromal lymphopoietin is released by human epithelial cells in response to microbes, trauma, or inflammation and potently activates mast cells. J Exp Med 2007; 204:253-8.

22. Wong CK, Hu S, Cheung PF, Lam CW. Thymic stromal lymphopoietin induces chemotactic and prosurvival effects in eosinophils: implications in allergic inflammation. Am J Respir Cell Mol Biol 2010; 43:305-15.

23. Ziegler SF. The role of thymic stromal lymphopoietin (TSLP) in allergic disorders. Curr Opin Immunol 2010; 22:795-9.

24. Van Bruaene $\mathrm{N}$, Bachert $\mathrm{C}$. Tissue remodeling in chronic rhinosinusitis. Curr Opin Allergy Clin Immunol 2011; 11:8-11. 